\title{
Nova Sistemática de Pessoal Civil na Administração Federal
}

\author{
José Medeiros \\ Assessor do Diretor-Geral do DASP
}

\section{INTRODUÇÃO}

Qualquer empresa privada ou organização governamental deve considerar a eficácia como pedra de toque para o resultado de suas atividades. Esse objetivo - aparentemente simples - se reveste de tão elevado grau de complexidade, que aturde e angustia aqueles que o busca.

Semelhante complexidade seria motivada pela ineficiência administrativa e pelo emaranhamento organizacional que asfixiam a iniciativa criadora e anulam todo e qualquer esforço produtivo.

Tradicionalmente, afirma-se, em tom dogmático e professoral, que a máquina administrativa brasileira está emperrada e o seu funcionamento é notoriamente deficiente. Isso pode ser considerado um prognóstico nem sempre fidedigno e sempre sem nenhuma fundamentação técnica. Na realidade, trata-se apenas de uma observação superficial, porquanto não baseada em prévia análise científica dos fatos - fatos esses de que se originou a atual situação administrativa brasileira, que se foi delineando, desde as suas origens coloniais, ao sabor dos acontecimentos ou das circunstâncias, sem a mínima planificação.

Semelhante situação, todavia, não poderia perdurar e uma reforma de mentalidade e de comportamento se tornava indispensável. Isso porque a análise desapaixonada, sob o prisma exclusivamente científico, do panorama da Administração Pública Brasileira leva o observador imparcial ao mais completo de- 
sencanto. Com efeito e de sã consciência, não se pode deixar de reconhecer que o serviço público se apresenta ainda inadequado, sendo preciso dinamizá-lo, a fim de alcançar as finalidades a que se propõe.

O exigido reaparelhamento da Administração Pública, para atender às suas gigantescas atribuições, somente poderá ser realizado através de autêntica revolução - considerada a expressão em seu sentido filosófico e em sua concepção funcional.

A desorganização estrutural, na realidade, vem afetando 0 regular funcionamento do complexo administrativo, que ainda se ressente de métodos modernos e científicos de trabalho e - suplantando a todos os demais elementos - de pessoal com as qualificações indispensáveis ao eficaz desempenho de suas atribuições funcionais.

O propósito de sanar semelhantes deficiências foi o inspirador do Decreto-lei n. ${ }^{\circ} 200$, de 25 de fevereiro de 1967, que estabelece as diretrizes para a Reforma Administrativa.

É válido repetir - embora isso seja do conhecimento de todos - que se trata de um diploma legal que fixa princípios, com o objetivo de nortear e demarcar uma nova filosofia administrativa, ficando na dependência de normas complementares que venham a corporificar as diretrizes ali estabelecidas. ${ }^{1}$

\section{PLANEJAMENTO ADMINISTRATIVO}

Constitui atitude bastante generalizada considerar o planejamento de algum programa ou projeto como algo autônomo, inteiriço, auto-suficiente. $O$ planejamento, de acordo com semeIhante ordem de idéias, se desvincularia por completo de sua execução ou implementação, configurando-se um documento imaculado, lírico, inconsútil. Nessa hipótese, o planejamento se assemelharia a um sonho belo e fantástico, mas que poderia desvanecer-se, quando em contacto com a realidade, como uma bolha de sabão que estoura ou como as espumas do mar que se desfazem nas areias da praia.

Em termos realísticos, ao planejamento há-de seguir-se naturalmente a ação correspondente. Isso porque o planejamento

1 Cf. JOSÉ MEDEIROS, "A Dinâmica da Reforma Administrativa", Revista do Serviço Público, vol. 105, N. ${ }^{\circ} 1$, Janeiro/Abril 1970 , págs. $43 / 50$. 
não pode deixar de ser compreendido como a fase inicial de um processo integrado, através do qual as fases se sucedem progressiva ou gradativamente até a sua completa realização.

Assim, a Reforma Administrativa - como é de meridiana evidência, embora estranhamente nem sempre reconhecida por todos - não deve representar simples reformulação da antiga estrutura, o que constituiria apenas novos cenários para o mesmo drama, mas deve provocar a formação de nova mentalidade de fato renovadora.

Em sentido figurado, podemos representar a Reforma Administrativa como um gigantesco polvo, cujos tentáculos hão de alcançar os mais variados aspectos da Administração Pública.

\section{ADMINISTRAÇÃO DE PESSOAL: base humana da Reforma Administrativa.}

É fora de dúvida que a implantação de uma autêntica revolução administrativa está umbelicalmente ligada a uma profunda modificação na sistemática de pessoal, visto como o resultado positivo daquela revolução repousa essencialmente no elemento humano que lhe dará execução.

Com efeito, não adianta idealizar-se ou mesmo implantar-se a mais aperfeiçoada máquina administrativa, com a utilização dos mais sofisticados métodos de trabalho, se, para movimentá-la, não se contar com elemento humano capacitado e treinado para realizar as respectivas atividades. Não há como discutir pois já se erigiu em axioma - que por trás de todo e qualquer empreendimento há sempre o homem, de cujos comportamento e atuação dependem o êxito ou malogro da empresa.

Sem sombra de dúvida, "a estrutura organizacional proporciona as bases para a divisão de trabalho entre o pessoal da organização, para estabelecer sua autoridade e responsabilidade, bem como para coordenar, dirigir e controlar suas atividades." 2

Dentro do panorama que se procurou esboçar, em rápidas pinceladas portinarescas, a situação da Administração de Pessoal no serviço público é inexoravelmente desalentadora. A sua 2 Herbert J. Chruden and Arthur W. Sherman, Jr., "Persnnnel Management", 3rd Edi-
tion, South-Western Pub. Company, Cincinnati, Ohio, 1968, pág. 53. 
visualização pode ser assim sintetizada: um exército de cerca de 700.000 servidores, em sua maioria despreparados para a missão que lhes cabe realizar e, além. disso, terrivelmente mal remunerados.

Diante desse quadro algo fantasmagórico, impunha-se a adoção de providências imediatas e enérgicas, que possibilitassem ao funcionalismo inadequadamente qualificado a aquisição dos conhecimentos indispensáveis ao satisfatório desempenho de suas atribuições.

Por outro lado, o problema salarial constitui poderoso e preponderante fator de integração do funcionário em sua carreira profissional, contribuindo para a permanência, no serviço público, do pessoal capaz - que se vê aliciado, a cada instante, por outros empregadores, com polpudas ofertas pecuniárias. De fato, não se pode sequer admitir a exata idéia de profissionalızação sem que o Estado-empregador retribua, condignamente, quem lhe presta serviços.

\section{NOVOS PLANOS DE CLASSIFICAÇÃO E RETRIBUIÇÂO DE CARGOS: sua inadiável necessidade.}

Os problemas enfocados somente poderiam ser solucionados através de novos planos de classificação de cargos e de retribuição, estando o Governo Brasileiro visivelmente empenhado nos respectivos estudos e implantação. Quanto a esse aspecto, é oportuno lembrar que, pela primeira vez em nossa história administrativa, princípios de uma nova política de pessoal são inscritos no documento que consolida e sintetiza uma programação de desenvolvimento nacional. ${ }^{3}$

A comprovação palpável desse propósito governamental está evidenciada na Lei n. 5.645 , de 10 de dezembro de 1970 , que estabelece diretrizes para o novo Plano de Classificação de Cargos. Esse diploma legal corporifica, embora ainda em seus delineamentos gerais, os princípios filosóficos que vêm norteando o comportamento reformista, com o objetivo de dotar a Administração Pública Federal de servidores altamente qualificados.

Ao invés de aprovar-se, por lei, os planos já esquematizados, inclusive com rígidas normas de enquadramento dos atuais

3 I Plano Nacional de Desenvolvimento (PDN) - 1972/74, aprovado pela Lei n. ${ }^{\circ} 5.727$, de 4 de novembro de 1971, Capitulo IV, item III. 
cargos e respetcivos ocupantes, à semelhança do sistema ainda vigente, aprovado pela Lei $n .^{\circ} 3.780$, de 1960 , preferiu-se estabelecer diretrizes, isto é, normas essencialmente substantivas, a serem desdobradas e complementadas pelo poder regulamentar - inerente ao Presidente da República como Chefe do Poder Executivo e gerente geral da Administração Pública.

Conforme enfatiza o Relatório da Comissão de Reforma Administrativa do Pessoal Civil, que coordenou a elaboração do anteprojeto que se converteu na Lei $n .^{\circ} 5.645$, "um plano de classificação de cargos tem de ser constantemente atualizado para acompanhar as transformações da realidade administrativa, a que ele deve sempre atender com presteza, e isso seria impraticável se qualquer alteração na sua sistemática por mínima que fosse - dependesse de medida legislativa. Essa maleabilidade faltou ao plano aprovado pela Lei $n .^{\circ} 3.780$, de 12 de julho de 1960, que agora se procura substituir por um sistema flexivel, capaz de acompanhar as mutações que o progresso tecnológico irá impondo ao Serviço Público".

Não se deve pretender, simplesmente, a implantação de novos planos de classificação e de retribuição de cargos apenas com o propósito de modificar ou substituir os existentes. Isso seria, na realidade, tarefa relativamente singela, desde que se adotasse, com ligeiras adaptações, qualquer um dos sistemas vigentes nos países desenvolvidos, seguindo, aliás, a recomendação generalizada de N.S. RAMASWAMY - Diretor do Instituto Nacional Industrial da India. ${ }^{4}$

Sucede, contudo, que esse tipo de comportamento não atenderia ao interesse da Administração e nem aos reclamos do funcionalismo. Sobretudo, a respeito do assunto os brasileiros já adquiriram "know-how" próprio, propiciando-lhes adequada solução de tais problemas, inclusive com os recursos advindos de seu inequívoco e extraordinário poder de criatividade.

É preciso atentar que os Planos de Classificação e de Retribuição integram um planejamento geral, cujo objetivo é o de dotar o Serviço Público Civil Brasileiro dos recursos humanos adequadamente qualificados e treinados para realizar, com eficácia, as missões afetas à Administração Pública e sempre erguidas para o superior interesse e bem estar da coletividade.

4 N. S. RAMASWAMY, "A Formaçăo de Administradores nos Paises em Vias de Desenvolvimento", Revista ID'ORT, Set./Dez. 1972, 487/490, pág. 10. 


\section{NOVO PLANO DE CLASSIFICAÇÃO DE CARGOS: medidas para sua implementação.}

\section{1 - Aparente esoterismo do Plano.}

A princípio, seria admissivel que a maioria do funcionalismo e até mesmo ponderável parcela de estudiosos não compreendessem, à primeira vista, a nova política de pessoal do Governo. Isso porque os termos da Lei n. ${ }^{\circ} 5.645$, de 1970 , poderiam parecer esotéricos e incompreensiveis, em face do caráter sintético de que se revestem, justificando, assim, a comparação com a esfinge mitológica ou o esqueleto de um ser. Com a implementação do projeto, inclusive expedição paulatina dos atos administrativos complementares, no entanto, o enigma da esfinge foi sendo aos poucos decifrado, o esqueleto foi adquirindo contornos definidos, incorporando-se-lhe carnes, músculos e nervos, enfim, sofrendo autêntico processo de vivificação.

Desse modo, e de acordo com seus próprios característicos, a implementação do novo Plano de Classificação de Cargos vem compreendendo diversas etapas de trabalho, considerada sempre a tônica predominante de que a sua implantação será gradualista, segundo os critérios de prioridade estabelecidos pelo Governo.

\section{2 - Constituição de Equipes Técnicas de alto nível.}

O primeiro passo decisivo ao desencadeamento da dinâmica executiva foi dado com a expedição do Decreto $n \cdot{ }^{\circ} 68.726$, de 9 de junho de 1971, que dispõe sobre a constituição e funcionamento das Equipes Técnicas de alto nível - encarregadas de coordenar as atividades relacionadas com os aspectos básicos de classificação de cargos em suas respectivas áreas: Ministério, Órgão Integrante da Presidência da República ou Autarquia.

\section{3 - Reforma Administrativa: primeira preliminar.}

A providência preliminar e condicionante das demais etapas a serem desenvolvidas seria, naturalmente, o estudo e a implantação da Reforma Administrativa, tal como prevista no Decreto-lei n. 200 , de 1967, com o objetivo de proporcionar a cada Ministério ou Autarquia uma estrutura realmente eficaz e ra- 
cional, sempre em busca de dois resultados fundamentais: o da simplicidade organizacional e o do processo operacional célere e econômico.

Desprezando as obsoletas teorias, a moderna administração, voltada exclusivamente para a consecução de seus objetivos, se vem organizando simples e funcionalmente. Esse comportamento realista e pragmático se contrapõe ao adotado pelas administrações incautas e inexperientes, impregnadas de espírito perdulário, que se atribuem estruturas pomposas, numa tentativa obviamente frustrada de auto-afirmação. Daí o injusto interrelacionamento da Administração Brasileira e sua burocracia com dinossauros, em distorcida figura de gigantismo. ${ }^{5}$ Isso porque essa hipertrofia desnecessária e inoperante - e até mesmo algo grotesca - não advém da intrínseca conveniência administrativa e nem sequer constitui característica da Administração Brasileira, pois se encontra disseminada pelo mundo afora, não apenas nos países subdesenvolvidos ou em fase de desenvolvimento, mas também nos países altamente industriatrializados e organizados.

Essa distorção caricaturesca se origina de concepções deformadas, que deturpam a realidade, e em seu bojo a precisa necessidade administrativa, em benefício do impulso incontrolável - e por isso mesmo refratário ao aconselhamento sensato e ao assessoramento técnico - de organizar-se de forma extravagante, à semelhança do "noveau riche", que recheia sua casa, a preço de ouro, de obras artísticas de gostos e raízes duvidosos.

É preciso cessar, de vez, os efeitos da entropia administrativa, cuja visão se concentra no personalismo vaidoso e no empirismo desenfreado, para sedimentar o período de autêntica tecnologia administrativa, que se caracteriza - e todos o sabemos - pelo espírito de realização produtiva, com a utilização de métodos racionais e eficazes de trabalho, para atingir-se plenamente os reais objetivos da empresa, da organização e, em termos projetados, de toda Administração Pública.

5 J. O de Meira Pena, "Psicologia do Subdesenvolvimento", APEC Editora S.A., Rio de Janeiro, 1972 , págs. $39 / 72$. 


\section{4 - Lotação de Pessoal: segunda preliminar.}

Dentro dessa nova perspectiva, estabelecida e delineada a estrutura básica, cabe realizar o levantamento e a análise das atividades de cada unidade organizacional, para efeito de discriminarem-se os variados e indispensáveis tipos de funções que devem ser desempenhadas.

Os resultados assim obtidos é que servirão de base aos estudos relacionados com os recursos humanos indispensáveis à satisfatória realização das atividades de cada uma das unidades organizacionais, sintetizado na lotação. ${ }^{6}$

Dessa forma, a lotação de pessoal poderá ser fixada realisticamente e em bases técnicas, desprezando-se o sempre condenável procedimento de estabelecer as categorias funcionais e sua quantificação por meio de processos empíricos ou simplesmente imaginativos: acho que a repartição " $X$ " deve ter tanto de tais funções.

O estabelecimento da lotação, contudo, admite duas fases distintas e que podem ser efetivadas em épocas diferentes. A primeira se refere a identificação qualitativa do elemento humano e constitui condição indispensável à estruturação de cada Grupo de Categorias Funcionais. A segunda fase se relaciona com a quantificação dos recursos humanos de que necessita a entidade ou órgão - trabalho que poderá ser realizado posteriormente.

\section{5 - Viabilidade financeira: terceira preliminar.}

Contudo, a par do desenvolvimento de suas configurações técnicas, a implantação dos novos Planos - notadamente no tocante à sua viabilidade financeira - está na dependência do comportamento dos supervisores de todos os níveis, desde os Ministros de Estado e os dirigentes das Autarquias até os chefes operacionais. Isto porque o êxito dos Planos se condiciona às informações que devam ser prestadas pelos supervisores, prestigiando a atuação dos analistas na perquirição das reais necessidades de pessoal.

6 "A lotaçăo representa a força de trabalho, em seus aspectos qualitativo e quantitativo, necessária ao desempenho das atividades normais e especlficas de uma ou de várias unidades administrativas" (Decreto n. ${ }^{\circ} 68.999$, de 28 de julho de 1971, artigo 2. ${ }^{\circ}$ ). 
Impõe-se repisar que os recursos humanos com que deve contar as organizações públicas hão de ser pesquisados e identificados sob prismas bem diversos dos até então vigorantes. Essa identificação far-se-á preliminarmente, como já vimos, à vista da reformulação administrativa e a conseqüente adoção de métodos racionais de trabalho, com o propósito de dinamizar a atividade administrativa da organização e reduzir os custos operacionais.

Em seqüência, verificar-se-á qual a força de trabalho imprescindivel ao impulsionamento dessa máquina administrativa simplificada, funcional e econômica. Essa análise repousará em aspectos fundamentais e todos eles decorrentes da filosofia com com que se acham impregnadas as diretrizes de classificação de cargos estabelecidas pela Lei $n .^{\circ} 5.645$, de 1970. Para efeito de disciplinamento de nosso raciocínio, limitemos a três aspectos primordiais: $10^{\circ}$ ) a qualificação adequada que deve possuir o novo funcionalismo, a ser comprovada mediante critérios seletivos condicionantes da transposição dos atuais servidores para a situação nova; $2 .^{\circ}$ ) as novas condiçães de trabalho inerentes ao exercício dos novos cargos e uma das quais deverá ser o período normal de trabalho de 40 (quarenta) horas semanais, mais ou menos equivalente ao atual regime de tempo integral; 3. e certamente o mais importante deles - atribuir ao funcionalismo retribuição pecuniária condizente com seu novo "status" - o que o motivará a desempenhar as suas atribuições com a máxima eficiência.

Observados tais condicionamentos, concluir-se-á que, em termos quantitativos, haverá uma ponderável redução do funcionalismo e um inequívoco aumento de eficiência e de produtividade, embora, à primeira vista, isso possa configurar um paradoxo.

Essa parcimônia no dispêndio com pessoal, em suas múltiplas facetas, representa fator essencial para a implantação, em cada Ministério ou Autarquia, dos novos Planos de Classificação e de Retribuições de Cargos, que há-de ser feita dentro de suas próprias disponibilidades orçamentárias. 


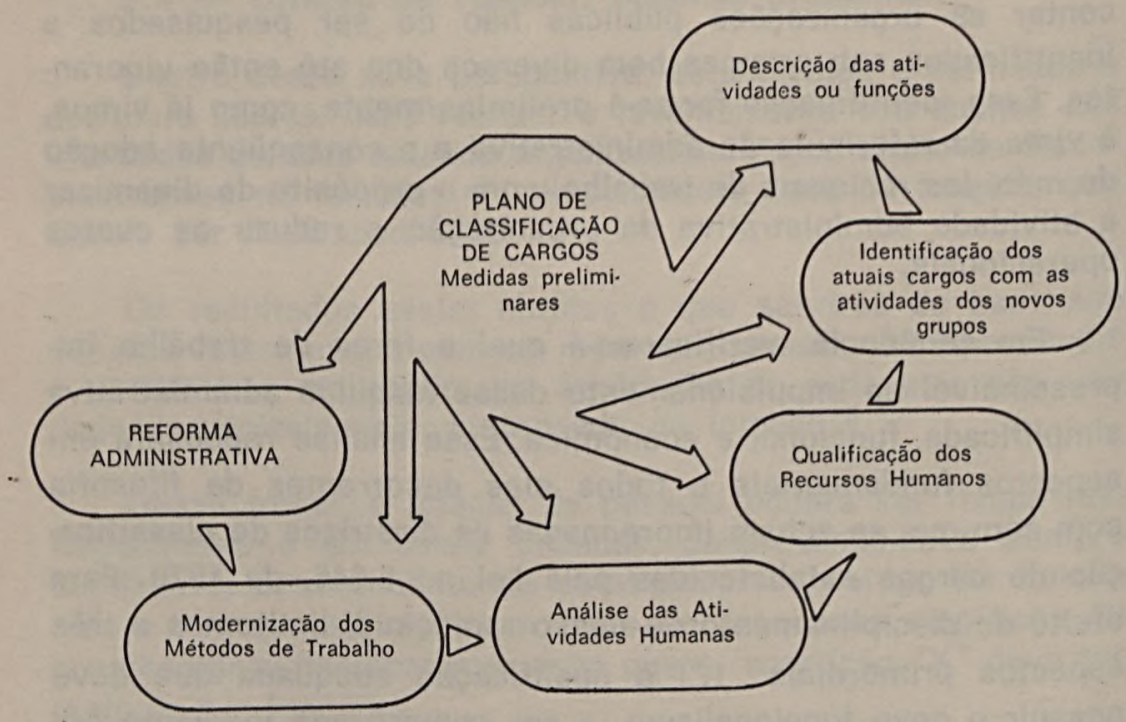

Modernizaçăo dos Métodos de Trabalho
Análise das Atividades Ilumanas

\section{MONTAGEM DO PLANO DE CLASSIFICAÇÃO DE CARGOS.}

\section{1 - Estruturação de cada Grupo.}

A Lei n. 5.645, de 1970, discrimina dez Grupos básicos:

I - Direção e Assessoramento Superiores;

II - Pesquisa Científica e Tecnológica;

III - Diplomacia;

IV - Magistério;

V - Polícia Federal;

VI - Tributação, Arrecadação e Fiscalização;

VII - Artesanato;

VIII - Serviços Auxiliares;

IX - Outras atividades de nível superior; e

$X$ - Outras atividades de nível médio. 
Esse relacionamento, todavia, não esgota os tipos de atividades característicos do Grupo, pois, se o justificarem as necessidades da Administração, outros poderão ser estabelecidos ou desdobrados dos previstos. ${ }^{7}$

A montagem de cada Grupo consiste na pesquisa e análise do complexo de atividade a ele inerente, segundo a correlação e afinidade da natureza dos trabalhos, a fim de indicar as Categorias Funcionais que devam integrá-lo.

Cada Grupo se desdobrará em tantas Categorias Funcionais quantos forem os conjuntos de atividades identificadas conforme o tipo e o grau de conhecimentos exigiveis para o respectivo desempenho.

A metodologia de trabalho a ser utilizado na "montagem" do novo plano de classificação de cargos se caracteriza pelo seu ineditismo em nosso meio administrativo e de seu bom uso dependerá o êxito do empreendimento.

\begin{tabular}{|c|c|c|}
\hline & \multicolumn{2}{|c|}{ GRUPOS JÁ ESTRUTURADOS } \\
\hline $\begin{array}{l}\text { Grupo: Direção e As- } \\
\text { sesoramenao Superiores. } \\
\text { Estruturação: Lei n. } \\
71.235 \text {, de } 10.10 .1972 . \\
\text { Retribuição: Lei número } \\
5.843 \text {, de 06.12.1972. }\end{array}$ & $\begin{array}{l}\text { Grupo: Serviços Auxi- } \\
\text { liares. } \\
\text { Estruturação: Decreto } \\
\text { número } 71.236 \text {, de } \\
11.10 .1972 . \\
\text { Retribuição: Lei número } \\
5.845 \text {, de } 06.12 .1972 .\end{array}$ & $\begin{array}{l}\text { Grupo: Diplomacia } \\
\text { Estruturação: Decreto } \\
\text { número } 71.323 \text {, de } \\
07.11 .1972 . \\
\text { Retribuição: Lei número } \\
5.846 \text {, de } 06.12 .72 \text {. }\end{array}$ \\
\hline
\end{tabular}

\section{2 - Decomposição das Categorias Funcionais.}

A categoria funcional representa "o conjunto de atividades desdobráveis em classes e identificadas pela natureza e pelo grau de conhecimentos exigível para o seu desempenho", 8 equivalendo ao que atualmente se entende como série de classes. $\mathrm{Na}$ prática, significa uma atividade profissional com característicos próprios, bem diversificados dos que são inerentes a outras Categorias. 
Um dos propósitos da nova sistemática é o de aglutinar as atividades que se identificarem com as relacionadas com o conteúdo geral do Grupo, procurando a máxima eliminação das atuais centenas de denominações, muitas delas para caracterizar o mesmo tipo de trabalho.

\section{3 - Critérios seletivos.}

Qualquer processo seletivo traduz a dupla idéia de escoIher os melhores dentre os elementos recrutados e de hierarquizá-los de acordo com critérios rígidos e justos, à base dos conhecimentos demonstrados. Em termos mais amplos, o seu objetivo é "a classificação ou eliminação daqueles julgados não qualificados para atender às exigências do trabalho e da organização". 9

Na espécie, a própria Lei n. 5.645, de 1970, condiciona expressamente a transposição ou transformação dos cargos, quando ocupados, a "critérios seletivos a serem estabelecidos para os cargos integrantes de cada Grupo, inclusive através de treinamento intensivo e obrigatório". (art. 9..$^{\circ}$.

Ao disciplinar o princípio legal, o Decreto $n .^{\circ} 70.320$, de 1972 , determinou que "os cargos providos somente serão transformados ou transpostos se os respectivos ocupantes, além de possuírem o grau de escolaridade e a habilitação profissional exigidos para o exercício das atividades da Categoria Funcional, forem habilitados em prova competitiva específica de caráter eliminatório". (Art. 11). Essa prova poderá ser precedida de curso específico e intensivo de treinamento - condição essencial nos casos de transformação, isto é, quando ocorrer alteração das atribuições do cargo, de seu conteúdo ocupacional.

Essa exigência básica, contudo, se vem diluindo, adocicando quando realmente se prevê a sua aplicação, em casos concretos. Para o Grupo - Diplomacia, não se fez nenhum condicionamento específico, sob a alegação de que os serviços diplomáticos têm tratamento excepcional pela Lei da Reforma Administrativa, sendo certo que os funcionários de tal natureza sempre ingressaram mediante rigorosa seleção, a princípio,

9 Dale S. Beach, "Personnel: The Management of People at Work", Second Edition, New-York, 1970, pág. 232. 
concurso e, depois, curso de formação realizado pelo Instituto Rio Branco. No tocante ao Grupo - Serviços Auxiliares, considera-se qualificado para transposição (casos em que não há mudança substancial das atribuições ou do conteúdo ocupacional do cargo) o funcionário que tenha ingressado no próprio cargo a ser transposto mediante concurso público e competitivo. A primeira vista, tal norma se afiguraria justa, mas se a examinarmos com olhos retrospectivos, essa aparente justiça se desvanece. Exemplifiquemos com a atividade de datilografia: em conseqüência de sua baixa retribuição, o recrutamento e a seleção eram realizados "por baixo", sem exigir-se o que deveria, pois, caso o fizesse, não se habilitaria nenhum candidato, tendo em vista que os melhores não atenderiam ao clarim do recrutamento, desinteressados pelo baixo vencimento em confronto com os oferecidos pelo mercado de trabalho. Mesmo assim, permitir-se-á que os atuais datilógrafos não cabalmente qualificados passem para a nova situação, já com atraentes condições salariais, sem nenhuma exigência específica de habilitação.

O Autor sempre preconizou que somente deveriam integrar os novos quadros funcionários altamente qualificados, condição essa apurada mediante cursos de treinamento exigidos para todos, indistintamente. Não se alegue a impraticabilidade desse procedimento com seu elevado custo, visto como as modernas técnicas de treinamento, a exemplo do curso por correspondência com a utilização do método do texto ativo ou da instrução programada, à semelhança do "boomerang" australiano, leva e traz conhecimentos e experiências com eficácia e economicamente. E de qualquer maneira muito mais produtivo ou rendável seria despender recursos financeiros com a adequada qualificação do funcionalismo do que com pagamento de salário a pessoal sem a desejável habilitação para o trabalho.

\section{4 - Critérios específicos para ingresso, bem como para progressão e ascensão funcionais.}

O ingresso inicial no Serviço Civil, observadas as normas constitucionais básicas ${ }^{10}$, será disciplinado em regulamenta-

10 - Constituição Federal, artigo 97 e parágrafos. 
ção geral, contendo a matéria comum a todas as atividades inerentes aos diversos Grupos de Categorias Funcionais. Mas, as peculiaridades de cada Grupo devem ser previstas no respectivo ato de estruturação.

A progressão e a ascensão constituem instrumentos de profissionalização do pessoal, pois significam a movimentação do funcionário do cargo que ocupa para outro da mesma Categoria Funcional, do mesmo Grupo ou mesmo de Grupo diferente, sempre em escala ascendente, em busca de posições de nível mais elevado e conseqüentemente mais bem retribuídas.

Pela sua especificidade, as exigências a serem estabelecidas para a progressão e a ascensão diferem, fundamentalmente, de um Grupo para outro. Por isso, ao ato de estrutura cabe disciplinar as respectivas condições, principalmente as que devem orientar a avaliação do desempenho, pois não se compneenderia que idênticos critérios se observassem na apuração funcional do servidor que executa trabalhos de natureza braçal e do diplomata, do pesquisador, do técnico de tributação e todos os outros que desempenham tarefas complexas e de natureza intelectual.

\section{5 - Especificações de classes.}

Estruturado o Grupo, cabe ao Órgão Central do SIPEC aprovar as especificações inerentes a cada classe e que consistem em sua exata e minuciosa caracterização, com a descrição sumária das atribuições, exemplos típicos de trabalhos ou tarefas, forma de recrutamento, qualificações essenciais para o recrutamento, período de trabalho etc.

As especificações de classes fornecem os elementos funcionais que orientam o recrutamento e a seleção, o "placement" - adaptação do funcionário ao trabalho, o estágio probatório e a avaliação do desempenho, funcionando como uma espécie de termômetro e indicando quando o cargo foge de sua própria natureza ou característica e deve, por isso, ser alterado quanto à sua denominação e ao seu conteúdo ocupacional. 


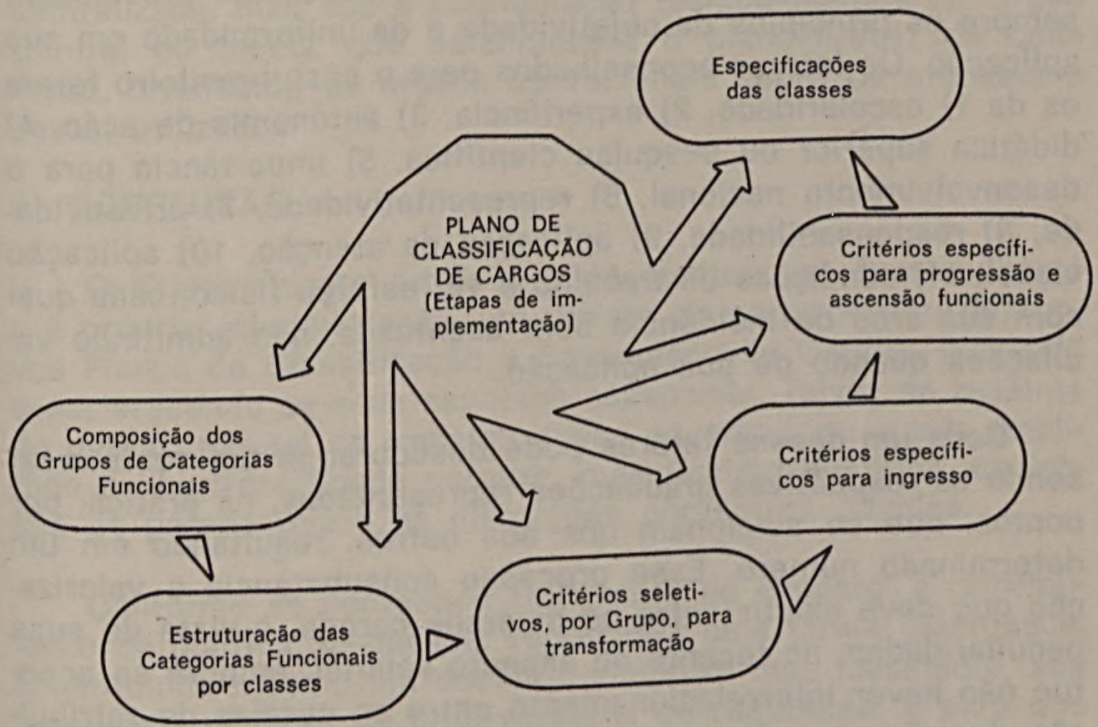

\section{NOVO PLANO DE RETRIBUIÇÃO}

No desenvolvimento do presente trabalho, percebemos, com nitidez meridiana, a relevância da retribuição como fator de integração do funcionário na organização.

Por isso, a par das questões relacionadas com a classificação de cargos, cuidou o Governo de estabelecer a metodologia de avaliação de cargos e empregos, que representasse a "adoção das escalas de retribuição, fundado nos princípios de uniformidade e objetividade e que eliminasse $o$ arbítrio e a discrição que vinham orientando as anteriores fixações salariais". ${ }^{11}$

Entre os numerosos métodos de avaliação adotados em toda parte do Mundo, preferiu-se o sistema de pontos ou de fatoração, que permite "a avaliação quantitativa de atividade com base em fatores ou elementos que observem as exigências do trabalho". 12

11 - Exposiçăo de Motivos DASP n.० 894, de 4/10/1972, in "Avaliaçăo de Cargos e Empregos" - DASP, CENDOC, 1972, p. 4.

12 - Herbert J. Chruden and Arthur W. Sherman, Jr, Personel Management, South-Western Publishing Company, Cincinnati - Ohio, 3rd edition, 1968, p. 550. 
A escolha dos fatores oferece certa margem de arbítrio, que não desvirtua o mérito do sistema, porquanto prevalecem sempre os princípios da objetividade e da uniformidade em sua aplicação. Os fatores aconselhados para o caso brasileiro foram os da 1) escolaridade, 2) experiência, 3) autonomia de ação, 4) didática superior ou pesquisa científica, 5) importância para o desenvolvimento nacional, 6) representatividade, 7) privatividade, 8) responsabilidade, 9) aplicação da atenção, 10) aplicação visual, 11) condições de trabalho e 12) esforço físico, cada qual com sua área de incidência bem acentuada, não admitindo vacilações quando de sua aplicação.

Cada um desses fatores pode desdobrar-se em subfatores, sendo as respectivas graduações representadas, na prática, por pontos, que se adicionam uns aos outros, resultando em um determinado número. Esse processo consubstancia a valorização que deve existir entre os diversos cargos, à vista de suas peculiaridades, no tocante ao aspecto salarial, embora se acentue não haver interrelacionamento entre as escalas de retribuição dos diversos Grupos.

A representação pecuniária da avaliação se encontra multiplicando a soma dos pontos obtidos por um módulo uniforme e constante - comum a todos os Grupos de Categorias Funcionais.

\section{IMPLANTAÇÃO DOS NOVOS PLANOS.}

Atendidos todos os pressupostos, inclusive as escalas de prioridades estabelecidas na área de cada Ministério, Órgão integrante da Presidência da República ou Autarquia, inicia-se a etapa final de implantação efetiva dos novos Planos de Classificação e de Retribuição de Cargos.

A medida que os Grupos forem sendo estruturados, os estudos sobre a lotação devem concluir-se, com a quantificação dos cargos por classes das Categorias Funcionais.

Iniciar-se-á, simultaneamente, a aplicação dos critérios seletivos fixados, com a institucionaliżação do subsistema de aperfeiçoamento, quando da realização dos cursos indispensáveis à qualificação dos atuais servidores. 
Os cursos de treinamento serão realizados de forma descentralizada, mas sob a coordenação técnico-didática do Órgão Central do SIPEC, que estabelecerá o plano-diretriz de cada curso, orientando os órgãos operacionais sobre os métodos a serem utilizados.

\section{CONCLUSÃo}

O objetivo deste artigo é o de mostrar, ao funcionalismo e à própria Administração, um retrato de corpo inteiro dos novos Planos de Classificaçã̃o e Retribuição de Cargos, pinçando e esclarecendo os seus aspectos essenciais. Talvez se ressinta do defeito natural de trabalho dessa envergadura: a sua amplitude ou horizontalidade permite, mas também justifica, os lapsos de perspectiva e as distorções porventura havidas.

Conforme se depreende facilmente do exposto, a reformulação da política de pessoal representa uma tarefa gigantesca, constituindo mesmo um desafio, complexo mas fascinante, aos brasileiros poderes de criatividade e de realização. E para que se possa vencê-lo estão sendo exigidas séria preparação técnica e utilização de moderna e eficiente instrumentalidade.

É certo, porém, que a intenção implícita dessa nova política é a de dignificar a função pública, conferindo aos servidores condizente "status" social, estimulando-lhes o permanente aprimoramento funcional, integrando-os - como profissionais que são - nas atividades públicas, incutindo-lhes a idéia precisa de que estão contribuindo, com a sua parcela de trabalho, esforço e dedicação, para o bem-estar da coletividade a que todos servimos, para a melhoria da natureza e da produtividade do Serviço Civil Brasileiro e, enfim, para o próprio engrandecimento do País. 